\title{
THE INTELLECTUAL STRUCTURE OF ONLINE SHOPPING RESEARCH: AUTHOR CO-CITATION ANALYSIS
}

\author{
Wann-Yih Wu \\ Nanhua University \\ No.55, Sec. 1, Nanhua Rd., Dalin Township, Chiayi County 62249, Taiwan (R.O.C.) \\ wwanyi888@gmail.com \\ Hsieh-Chih Chen \\ National Sun Yat-sen University/Kao Yuan University \\ No.1821, Zhongshan Rd., Luzhu Dist., Kaohsiung City 821, Taiwan (R.O.C.) \\ t90105@cc.kyu.edu.tw \\ Ching-Ching Ke \\ Kao Yuan University \\ No.1821, Zhongshan Rd., Luzhu Dist., Kaohsiung City 821, Taiwan (R.O.C.) \\ t90013@cc.kyu.edu.tw
}

\begin{abstract}
This study was conducted to investigate the intellectual structure of the online shopping field in the last decade using co-citation analysis. The citations were obtained from the database of WOS (World of Science), and articles (authors) were used as the units of analysis. Based on the results, this research revealed the main categories in the field of online shopping and the relationships between the subfields of research subjects and among authors and identified the authors who play a central role in the conceptual domains of online shopping. This research outlines the intellectual structure of the field of online shopping and its development trends. It also provides details about the influence of individual authors and the evolving structure of this research field over time.
\end{abstract}


Keywords: Co-Citation, Online Shopping, Social Network, Intellectual Structure

\section{INTRODUCTION}

In recent years, the volume of electronic commerce has grown tremendously, as noted in a report published by eMarketer (Chen, 2012). Website quality attributes increase online shopping and positive electronic word of mouth (Yang, Li, Kim, \& Kim, 2015). Thus, the Internet is a critical factor in the development of online retailers. Customers' purchasing frequency and perceived risk strongly influences their online purchase intention (Martin, Mortimer, \& Andrews, 2015). When facing a new trading platform and heterogeneous customers, the use of a pricing strategy is a good way to maximize revenue (Zhou, Chao, \& Gong, 2014). Many different factors can affect customer intention in an online shopping context, including information system, customer behavior, emotion state, social factors, e-shopping experience, web atmospherics, trust, and the like (Lim, 2015). To better understand research on online shopping, this study investigated the intellectual structure of this field based on an author co-citation analysis.

In this way, the social network of online shopping field can be outlined, and the key influential factors can be derived using multivariate techniques. Although online shopping is a new and developing discipline, it is important because of the rapid growth of electronic commerce. Online commerce is expanding fast and creating significant opportunities for online stores (Lim, Al-Aali \& Heinrichs, 2014). Many researchers are thus involved in examining key factors related to online shopping. This study reviewed research published in the past decade, outlining its structure to better understand its development.

\section{OVERVIEW OF THE RESEARCH METHODOLOGY}

Author co-citation analysis (ACA) was applied in this study to describe the intellectual structure of online shopping research. This bibliometric technique is used to first collect matrix data on co-citation frequencies between articles (authors) as the basic unit of analysis. Factor analysis is then used to extract the key conceptual subfields. Social network analysis is used to conduct data mapping and draw the network relationships among authors. Each of these methodologies is described in more detail, as follows. 


\section{Author Co-Citation Analysis}

ACA is a research method based on bibliometrics or bibliographies (McCain, 1990), and it has been widely applied to clarify subfields in many disciplines and explain the relationships among them (Nerur, Rasheed, \& Natarajan, 2008; Eom, 1996; McCain, 1984; Eom, 1996; Eom, \& Farris, 1996). Authors from the same research fields are often cited together in other studies, and the frequency of co-citation is thus used to measure the relationships among authors. This ACA method begins with the selection of databases and computes a co-citation frequency between any pair of authors whose studies were cited together in references (Eom \& Farris, 1996). To produce the raw co-citation matrix, only the first author of a cited work is counted. The next stage is to compile a matrix of Pearson's $r$ because this procedure can eliminate scale effects due to the relative citedness of documents (White \& Griffith, 1981), which is then used to perform the multivariate analysis.

\section{Factor Analysis}

The factor analysis was conducted with the co-citation matrix of Pearson's $r$ as the input to reduce the data for exploratory purposes, and derived subfields by extracting factors. The number of factors extracted depended on the sum of the square loading on the factor (the eigenvalue) being more than 1 (McCain, 1990). Oblique factor rotation was used to analyze the factor relationships, and factor loadings greater than 0.4 were selected as members for a specific factor (Culnan, 1986; Culnan, 1987; Nerur, Rasheed, \& Natarajan, 2008).

\section{Social Network Analysis}

Social network analysis is used to map the relationships among the highly co-cited authors and thus produces a representation of the otherwise invisible knowledge network. The Netdraw software package is used in social network analysis to draw the network structure based on graph theory, and this identifies the links between nodes. The core nodes represent the most cited authors within a discipline, and the links between two authors show their relationship and degree of similarity.

\section{ANALYSIS}

This section details each stage of our analysis and the related results. 


\section{Selection of Authors}

The aim of this paper was to reveal the research concept structure of online shopping. To find conceptual structure of online shopping, this paper used the relationship among authors to outline the key specialties of online shopping issue. Online shopping research structure revealed articles classified on the field of online shopping. The primary data of this study was retrieved from the database of Web of Science, which includes Social Science Citation Index, Science Citation Index Expanded, and Art \& Humanities Citation Index (AHCI) from 1990-2013. Two steps were used to select authors for the purpose of this research. First, the term "online shopping" was regarded as the key word in the database of WOS. The articles cited 100 or more times in the 1990-2013 period were selected (Lin, \& Cheng, 2012). Forty authors fit the criteria. Second, the co-citation matrix data was developed based on computing the co-citation frequency between any pair of authors. A higher co-citation frequency between a pair of authors means a stronger relationship between them. According to the criteria of requiring a mean co-citation rate of above 5 per co-citation/author (Culnan, 1987; McCain, 1984) and at least one-third of the research author set (Eom \& Farris, 1996), 28 authors were selected.

\section{Factor Analysis}

Factor analysis is a data reduction method, which can help reveal the relationships among authors. Authors who work in one specialized area often tend to co-cite the same article. Thus, factor analysis tends to classify these authors into the same factor based on factor loadings. Following the suggestions of other ACA studies (Culnan, 1987; Eom, 1996; McCain, 1990), only factor loadings above 0.4 were classified into a factor in the current work. The authors with higher factor loadings have more influence on the factor. Principle component analysis with oblimin rotation was used to extract the key factors and their correlations when the eigenvalues were greater than 1 . Seven key factors were extracted, and these are shown in Table 1.

\section{Social Network Analysis}

Social network analysis was used to generate a network structure to build the paths between two authors. Figure 1 shows the network diagram of online shopping, with the paths between two authors who were cited more than 15 times in the same studies. Authors with more path connections have more influence in the research area. There are 21 path connections for Gefen in the network of online shopping research from 28 
authors selected in this study. Koufaris, Childers, and Novak also play vital roles in the research structure of online shopping. Koufaris has 17 path connections and Childers and Novak have 14 path connections, as seen in their high frequencies of path connections.

\section{Table 1 Factor Analysis for Online Shopping Co-Citations}

\begin{tabular}{|c|c|c|c|c|c|c|c|}
\hline & Factor 1- & Factor 2- & Factor 3- & Factor 4- & Factor 5- & Factor 6- & Factor 7- \\
\hline & Devaraj & Burke & Bhatnagar & Brynjolfsson & Belanger & Parasuraman & Koufaris \\
\hline & Gefen, & Childers & Liang & Haubl & Gefen & Ranganathan, & Liao \\
\hline & Koufaris, & Eroglu & Liao & Lynch & Lee & Wolfinbarger & Ranganathan \\
\hline & McKinne, & Koufaris & Miyazaki & & Miyazaki, & & Shih \\
\hline & Torkzadeh & Mathwick & $\begin{array}{l}\text { Van der } \\
\text { Heijden }\end{array}$ & & Stewart & & Shim \\
\hline & & Novak & & & $\begin{array}{l}\text { Van der } \\
\text { Heiiden }\end{array}$ & & Vijayasarathy \\
\hline & & $\begin{array}{c}\text { Shim } \\
\text { Wolfinbarger(2) }\end{array}$ & & & & & \\
\hline Eigenvalue & 6.44 & 4.55 & 3.45 & 3.02 & 1.98 & 1.65 & 1.20 \\
\hline $\begin{array}{l}\text { Variance } \\
\text { explained }\end{array}$ & 3.58 & 4.30 & 2.97 & 3.09 & 3.28 & 2.43 & 2.66 \\
\hline $\begin{array}{l}\text { Percentage } \\
\text { of total } \\
\text { variance } \\
\text { explained }\end{array}$ & 23.01 & 16.25 & 12.33 & 10.80 & 7.07 & 5.90 & 4.30 \\
\hline
\end{tabular}

Note: Total variance explained: $79.68 \%$; Authors with loadings $\geqq 0.7$.

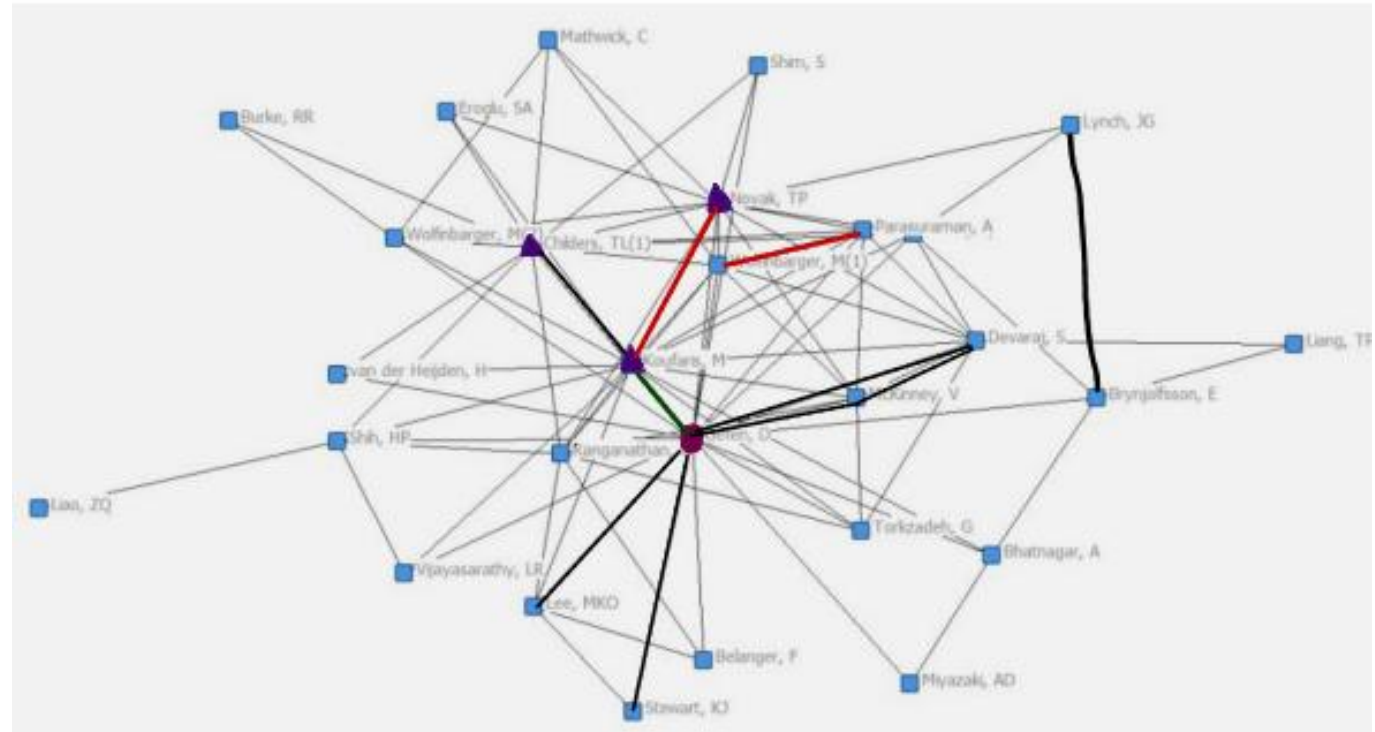

Figure 1 Network Diagram of Online Shopping from Social Network Analysis (Frequencies of co-citation > 15) 
The nodes represent the authors in the field of online shopping research who are co-cited most frequently. Thicker the connecting lines indicate more similar and stronger relationship among authors. In the field of online shopping research, the linkage between Wolfinbarger (2003) and Parasuraman (2005) is the strongest; thus, they have the closest relationship with each other.

\section{CONCLUSIONS AND IMPLICATION}

The aim of this paper was to outline the intellectual structure of the field of online shopping. The social network shows the relationship between two highly co-cited articles and the relative connecting strengths. Both Wolfinbarger (2003) and Parasuraman (2005) developed how to value quality in an online context. They are co-cited most frequently and have the strongest connection. The field of online shopping is very young but very important because of the fast growth of electronic commerce. To realize the fundamental theories and categories in the online shopping field, this study utilized factor analysis to clarify the data. The results showed seven factors that are worth investigating more, including Measurement Instruments, Emotional and Cognitive States, Perceived Risk and Uncertainty, Pricing Strategies, Trust, Quality, and Influence of Technology.

The major research trends over the last decade are divided into seven factors, including the development of measurement instruments, the influence of emotional and cognitive states, the application of perceived risk, pricing strategies, the employment of trust models, the influence of e-retailer quality and technology acceptance. This study provides a framework for online shopping field development, revealing that the field has integrated works from the technology, business management, and consumer psychology literature. These three key elements affect the outcomes for electronic retailers. This work also outlines the social network of the online shopping field. Based on the frequency of connections between two authors, the most influential author is Gefen (2003), who had 21 connections out of 28 highly cited authors. Koufaris (2002), Childers (2001), and Bhatanagar (2002) are other important authors near the center of the social network of online shopping. This study thus identified the most influential authors and the relationships among authors in the online shopping field, helping us understand the core authors and research topics. Since the issue of online shopping is still rather undeveloped, the structural map presented in this work is likely to change with the future development of this field. However, examining research from the past decade can still offer important suggestions for future work. 


\section{REFERENCES}

Bayer, A.E., Smart, J.C., \& McLaughlin, G.W. (1990). Mapping intellectual structure of a scientific subfield through author cocitations. Journal of the American Society for Information Science, 41(6), 444-452. http://dx.doi.org/10.1002/(SICI)1097-4571(199009)41:6\%3C444::AID-ASI12\%3E3 .0.CO;2-J.

Bhatnagar, A., Misra, S., \& Rao, H.R. (2000). On risk, convenience, and Internet shopping behavior - Why some consumers are online shoppers while others are not. Communications of the ACM, 43(11), 98-105. http://dx.doi.org/10.1145/353360.353371.

Burke, R.R. (2002). Technology and the customer interface: What consumers want in the physical and virtual store. Journal of the Academy of Marketing Science, 30(4), 411-432. http://dx.doi.org/10.1177/009207002236914.

Chen, Y.Y. (2012). Why do consumers go internet shopping again? Understanding the antecedents of repurchase intention. Journal of Organizational Computing and $\begin{array}{lll}\text { Electronic } \quad \text { Commerce, } & \text { 22(1), }\end{array}$ http://dx.doi.org/10.1080/10919392.2012.642234.

Childers, T.L., Carr, C.L., \& Peck, J. (2001). Hedonic and utilitarian motivations for online retail shopping behavior. Journal of Retailing, 77(4), 511-535. http://dx.doi.org/10.1016/S0022-4359(01)00056-2.

Culnan, M.J. (1986). The intellectual development of management information systems, 1972-1982: A co-citation analysis. Management Science, 32(2), 156-172. http://dx.doi.org/10.1287/mnsc.32.2.156.

Culnan, M.J. (1987). Mapping the intellectual structure of MIS, 1980-1985: A co-citation analysis. MIS Quarterly, 11(3), 341-353. http://dx.doi.org/10.2307/248680.

Eom, S.B., \& Farris, R.S. (1996). The contributions of organizational science to the development of decision support systems research subspecialties. Journal of the American Society for Information Science, 47(12), 941-952. http://dx.doi.org/10.1002/(SICI)1097-4571(199612)47:12\%3C941::AID-ASI7\%3E3 .0.CO;2-2.

Eom, S.B. (1996). Mapping the intellectual structure of research in decision support systems through author co-citation analysis (1971-1993). Decision Support Systems, 16(4), 315-338. http://dx.doi.org/10.1016/0167-9236(95)00026-7.

Gefen, D., Karahanna, E., \& Straub, D.W. (2003). Trust and TAM in online shopping: 
An integrated model. MIS Quarterly, 27(1), 51-59.

Koufaris, M. (2002). Applying the technology acceptance model and flow theory to online consumer behavior. Information Systems Research, 13(2), 205-223. http://dx.doi.org/10.1287/isre.13.2.205.83.

Lee, L.C., Chung, N., \& Lee, S. (2011). Exploring the influence of personal schema on trust transfer and switching costs in brick-and-click bookstores. Information \& Management, 48(8), 364-370. http://dx.doi.org/10.1016/j.im.2011.09.002.

Lim, J., Al-Aali A., \& Heinrichs, J.H. (2014). Impact of satisfaction with e-retailers' touch points on purchase behavior: The moderating effect of search and experience product type. Marketing Letters, 26(2), 225-235.

Lim, W.M. (2015). Antecedents and consequences of e-shopping: an integrated model. Internet Research, 25(2), 184-217. http://dx.doi.org/10.1108/IntR-11-2013-0247.

Lin, T.Y., \& Cheng, Y.Y. (2012). Changes in the intellectual of strategy alliance research, 1980-2009. Management Review, 31(4), 67-97.

Martin, J., Mortimer, G., \& Andrews L. (2015). Re-examining online customer experience to include purchase frequency and perceived risk. Journal of Retailing $\begin{array}{llll}\text { and Consumer } & \text { Services, } & 25, & 81-95 .\end{array}$ http://dx.doi.org/10.1016/j.jretconser.2015.03.008.

McCain, K.W. (1984). Longitudinal author co-citation mapping - The changing structure of macroeconomics. Journal of the American Society for Information Science, 35(6), 351-359. http://dx.doi.org/10.1002/asi.4630350607.

McCain, K.W. (1990). Mapping authors in intellectual space - A technical overview. Journal of the American Society for Information Science, 41(6), 433-443. http://dx.doi.org/10.1002/(SICI)1097-4571(199009)41:6\%3C433::AID-ASI11\%3E3 .0.CO;2-Q.

Nerur, S.P., Rasheed, A.A., \& Natarajan, V. (2008). The intellectual structure of the strategic management field: An author co-citation analysis. Strategic Management Journal, 29(3), 319-336. http://dx.doi.org/10.1002/smj.659.

Novak, T.P., Hoffman, D.L., \& Yung, Y.F. (2002). Measuring the customer experience in online environments: A structural modeling approach. Marketing Science, 19(1), 22-42. http://dx.doi.org/10.1287/mksc.19.1.22.15184.

Parasuraman, A., Zeithaml, V.A., \& Malhotra, A. (2005). E-S-QUAL - A multiple-item scale for assessing electronic service quality. Journal of Service Research, 7(3), 213-233. http://dx.doi.org/10.1177/1094670504271156. 
White, H.D., \& Griffith, B.C. (1981). Author cocitation - A literature measure of intellectual structure. Journal of the American Society for Information Science, 32(3), 163-171. http://dx.doi.org/10.1002/asi.4630320302.

Wolfinbarger, M., \& Gilly, M.C. (2001). Shopping online for freedom, control, and fun. California Management Review, 43(2), 42-55. http://dx.doi.org/10.2307/41166074.

Wolfinbarger, M., \& Gilly, M.C. (2003). eTailQ: Dimensionalizing, measuring and predicting etail quality. Journal of Retailing, 79(3), 183-198. http://dx.doi.org/ 10.1016/S0022-4359(03)00034-4.

Yang, K., Li, X., Kim, H., \& Kim, Y.H. (2015). Social shopping website quality attributes increasing consumer participation, positive eWOM, and co-shopping: The reciprocating role of participation. Journal of Retailing and Consumer Services, 24, 1-9. http://dx.doi.org/10.1016/j.jretconser.2015.01.008.

Zhou, W., Chao, X., \& Gong X. (2014). Optimal uniform pricing strategy of a service firm when facing two classes of customers. Production and Operations Management, 23(4), 676-688. http://dx.doi.org/10.1111/poms.12171. 
